\title{
Thromboelastography as an instrument of preclinical studies of the potential drug
}

\author{
Aleksandr Livievich Urakov ${ }^{1}$, Ilshat Ganeevich Mustafin ${ }^{2}$, Rosa Mullayanovna Nabiullina ${ }^{2}$, Linara Irekovna Bashirova ${ }^{1}$, \\ Konstantin Sergeevich Mochalov ${ }^{3}$, Aleksandr Vladimirovich Samorodov ${ }^{3 *}$, Ferkat Adelsyanovich Khaliullin ${ }^{3}$, Danila \\ Olegovich Lipatov ${ }^{3}$, Vladislav Igorevich Korunas ${ }^{3}$, Lina Nailevna Ismagilova ${ }^{3}$, Almaz Radicovich Khalimov ${ }^{3}$ \\ ${ }^{1}$ Department of General and Clinical Pharmacology, Izhevsk State Medical Academy, Izhevsk, Russia. \\ ${ }^{2}$ Department of Biochemistry, Kazan State Medical University, Kazan, Russia. \\ ${ }^{3}$ Central research laboratory, Bashkir State Medical University, Ufa, Russia.
}

\begin{tabular}{l}
\hline ARTICLE INFO \\
\hline Received on: $26 / 12 / 2019$ \\
Accepted on: $29 / 06 / 2020$ \\
Available online: 05/08/2020 \\
\hline Key words: \\
Thromboelastography, \\
hemostatic system, \\
thrombosis, anti-aggregants, \\
coagulation.
\end{tabular}

\begin{abstract}
There are no recommendations for assessing the effect of potential drugs on the hemostatic system irrespective of the anticipated application area, which leads to long-term financial losses. The examples of papaverine hydrochloride, pentoxifylline, and acetylsalicylic acid demonstrated the potential of thromboelastography (TEG) as a screening method for products that affect the hemostatic system, the safety assessment method for hypercoagulability/hypocoagulability, and the thrombosis model, using tissue factor (TF) or thrombin. The blood of male donor patients $(n=60)$ with acute de novo thrombosis $(n=90)$ was used. Using activated TEG, in vitro hemostatic system hyperactivity modeling was carried out with the blood of healthy male donors $(n=20) ; 0.2 \mathrm{M} \mathrm{CaCl} 2$, recombinant TF, and thrombin were used as TEG activators. General coagulation tendency (R), functional activity of thrombocytes and fibrinogens (MA, Angle), fibrinolysis activity, and physical-mechanical properties of formed clots were determined from thromboelastograms. The effect of anti-aggregants was characterized by a significant decrease in MA. The potential of TEG as a screening method for assessing the effect of new pharmacological agents on the hemostatic system at preclinical stage was demonstrated; the possibility of safety assessment for hypercoagulability/hypocoagulability was shown; and the comparability of hemostatic parameters of the patients with thrombosis and TEG, activated by TF and/or thrombin was demonstrated.
\end{abstract}

\section{INTRODUCTION}

The current paradigm of preclinical assessment of the effect of potential preparations on the hemostatic system is based on recommendations that are more than 20 years old, lacking the methods of the global tests for the hemostatic system. Up until now, there are no mandatory recommendations to assess the effect of potential drug products on the hemostatic system, irrespective of the anticipated application area. This leads to financial losses in the long term, suggesting the need for developing guidelines and searching for new methods for informative and effective

\section{"Corresponding Author}

Aleksandr Vladimirovich Samorodov, Central research laboratory, Bashkir State Medical University,Ufa, Russia.E-mail:AVSamorodov@gmail.com assessment of the safety of potential drug products regarding the hemostatic system, based on the available scientific data (Hackett et al., 1982).

Thromboelastography (TEG) is one of the methods that assesses the key coagulation stages, starting from the formation of the first fibrin threads and ending with the clot degradation. TEG allows bleeding to be readily diagnosed and adjusts the volume of hemotransfusion media, which is an integral component of the "point of testing care conception" in the setting of resuscitation and intensive care. In addition, TEG is included in the clinical guidelines for medical aid (Bakirov et al., 2018; Subramanian et al., 2019). Considering the high efficiency of this global hemostatic test and its absence in national and international recommendations on preclinical study of new pharmacological agents, it seems appropriate to evaluate its prognostic role and to integrate it into preclinical studies for studying new pharmacological molecules 
as a screening method and ex vivo model of thrombosis. Thus, the primary objective of this study is to examine the hemostatic system in patients with thrombosis and the application of data as a model for assessing the pharmacological activity of drug products. In addition, through the example of the preparation that is not used as an anti-aggregant, papaverine hydrochloride and anti-aggregants with different modes of action, the potential of TEG as a screening method for drug products affecting the hemostatic system, safety assessment method for hypercoagulability/hypocoagulability, and model of thrombosis using tissue factor (TF) or thrombin (THR) as an activator were demonstrated.

\section{MATERIALS AND METHODS}

This study was carried out under in vitro conditions with the blood of male donor patients with acute de novo thrombosis. The modeling of hyperactivity of the hemostatic system under in vitro conditions was conducted using the blood of 20 healthy male donors aged 18-24 years. This study was approved by the Ethics Committee of the Federal State Budgetary Educational Institution of Higher Education at the Bashkir State Medical University of the Ministry of Health of Russian Federation (No. 2 dated 17.10.2012). Informed consent was obtained from all participants before blood sampling.

To determine the efficacy of potential anti-aggregants under the conditions of complete thrombosis, the blood of patients admitted to the Anesthesiology and Intensive Care Unit of the G.G. Kuvatov First Republican Clinical Hospital (Ufa) over the period 2012-2014 was used. A control group was formed, which did not differ in the baseline characteristics from the thrombosis group. The clinical and demographic characteristics are presented in Table 1. Baseline thromboelastograms were obtained after venous blood collection before starting antithrombotic/thrombolytic therapy according to the intensive therapy plan.

\section{Blood collection and centrifugation}

The blood collection was carried out using the system of vacuum blood sampling BD Vacutainer ${ }^{\circledR}$ (Becton, Dickinson and Company, Franklin Lakes, NJ). As a venous blood stabilizer, a $3.8 \%$ sodium citrate solution in 9:1 ratio was used.

\section{Thromboelastography}

TEG was carried out using TEG 5000 (Hemoscope Corporation, Niles, IL). In the analysis of thromboelastograms, the general tendency of coagulation (R), functional activity of thrombocytes and fibrinogen (MA, Angle), fibrinolytic activity (CLT - clot lysis time), and the physical-mechanical properties of formed clots $(\mathrm{G})$ were determined. As a standard activator for TEG, $0.2 \mathrm{M}$ $\mathrm{CaCl}_{2}$ solution, recombinant TF (Innovin ${ }^{\circledR}$, Dade Behring, Marburg, Germany), and thrombin (Technology-Standard, Russia) were used.

\section{Study drugs}

As reference drugs, 3,7-dimethyl-1-(5-oxohexyl) xanthine (pentoxifylline, Dalkhimfarm PJSC, Nizhnekamsk, Russia), 2-acetylbenzoic acid (acetylsalicylic acid, Pharmaceutical Plant Shandong Xinhua Pharmaceutical Co, Ltd., Shandong, China), and 6,7-dimethoxy-1-(3,4-dimethoxybenzyle)isoquinoline hydrochloride (papaverine hydrochloride, Dalkhimfarm PJSC, Nizhnekamsk, Russia) were used.

\section{Statistical analysis}

Statistical analysis was carried out using the statistical package Statistica 10.0 (StatSoft Inc., Tulsa, OK). Shapiro-Wilk's test was used to check the normality of actual data. Median and interquartile intervals were used for group description. Analysis of variance was carried out using the Kruskal-Wallis test (for independent observations) and Friedman's test (for replicate observations). The relationship between the parameters was assessed using Pearson's $(r)$ correlation ratio and determination factor $\left(r^{2}\right)$. For assessing the incidence of diabetes mellitus, oncological pathology, and smoking in patients with thrombosis, the initial data were analyzed by the method of paired tables using Pearson's chi-squared test $\left(\chi^{2}\right)$. The power and sample size for key indicators of the hemostatic system were assessed using the Statistica Power Analysis module. A $p$-value of $<0.05$ was considered to be statistically significant. The $\mathrm{IC}_{50}$ values of compound I and reference drugs were calculated using a nonlinear fitting of curves describing the anti-aggregation activity (\%) by the four-parameter logistic equation using GraphPad Prism 8 (GraphPad Software, Inc., La Jolla, CA).

\section{RESULTS}

\section{Assessment of samples of patients with thrombosis}

The results of the study of the hemostatic system using TEG in patients with thrombosis are presented in Table 2.

\section{Group acute coronary syndrome/myocardial infarction (ACS/MI)}

Reaction time $(R)$, characterizing the first stage of blood coagulation (plasma coagulation) in the venous section of blood circulation, increased on average by $30 \%(p=0.007)$ compared to the control. The parameter MA, characterizing thrombocytes

Table 1. Clinical and demographical characteristics.

\begin{tabular}{|c|c|c|c|c|}
\hline Characteristics & All patients $(n=150)$ & Control group $(n=60)$ & Thrombosis group $(n=90)$ & $p$ value \\
\hline Age, y & $57.9 \pm 8.5$ & $53.7 \pm 7.9$ & $58.1 \pm 8.4$ & 0.749 \\
\hline Male gender $(\%)$ & $78(52.0)$ & $32(53.3)$ & $46(51.1)$ & 0.906 \\
\hline Diabetes mellitus (\%) & $24(21)$ & $9(15.0)$ & $15(16.6)$ & 0.605 \\
\hline Smoking (\%) & $11(7.4)$ & $3(5.0)$ & $8(8.9)$ & 0.083 \\
\hline Sinus rhythm (\%) & $141(94)$ & $58(96.6)$ & $83(92.2)$ & 0.215 \\
\hline Oncological pathology (\%) & $26(17.3)$ & $9(15.0)$ & $17(18.8)$ & 0.603 \\
\hline Hyperaggregation of thrombocytes (\%) & $75(50.0)$ & $0(0.0)$ & $75(83.3)$ & 0.0001 \\
\hline
\end{tabular}


Table 2. Thromboelastography parameters of the control group and thrombosis group $\mathrm{Me}(25-75)$ and $\mathrm{IC}_{50}$ of the studied reference drugs.

\begin{tabular}{|c|c|c|c|c|c|}
\hline \multicolumn{2}{|c|}{ Parameters } & \multirow[t]{2}{*}{ Value } & \multicolumn{3}{|c|}{$\mathrm{IC}_{\mathrm{MA}} 50, \mathrm{M} / \mathrm{l}$} \\
\hline & & & Pentoxifylline & Acetylsalicylic acid & Papaverine hydrochloride \\
\hline \multirow[t]{5}{*}{ Control } & $\mathrm{R}, \min$ & $12.8(10.3-15.6)$ & $1.4 \times 10^{-3}$ & $4.2 \times 10^{-3}$ & $1.2 \times 10^{-2}$ \\
\hline & TMA, min & $35.7(32.8-41.4)$ & & & \\
\hline & MA, mm & $57.3(54.2-61.2)$ & & & \\
\hline & $\mathrm{G}$, dyne $/ \mathrm{cm}^{2}$ & $5.7(4.5-7.9)$ & & & \\
\hline & CLT, min & $38.7(35.4-42.4)$ & & & \\
\hline \multirow[t]{5}{*}{ ACS } & $\mathrm{R}, \min$ & $17.9(16.3-25.4)^{*}$ & $4.1 \times 10^{-3}$ & $3.8 \times 10^{-3}$ & $5.6 \times 10^{-2}$ \\
\hline & TMA, min & $25.1(23.7-28.4)^{* *}$ & & & \\
\hline & MA, mm & $119.8(94.8-121.7)^{* *}$ & & & \\
\hline & $\mathrm{G}$, dyne $/ \mathrm{cm}^{2}$ & $8.4(7.9-9.1)^{*}$ & & & \\
\hline & CLT, min & $39.7(38.4-43.5)$ & & & \\
\hline \multirow[t]{5}{*}{ DVT/MT } & $\mathrm{R}, \min$ & $13.8(11.5-15.2)$ & $4.4 \times 10^{-3}$ & $3.7 \times 10^{-3}$ & $5.4 \times 10^{-2}$ \\
\hline & TMA, min & $22.3(19.7-22.4)^{* *}$ & & & \\
\hline & $\mathrm{MA}, \mathrm{mm}$ & $81.4(79.6-86.9)^{* *}$ & & & \\
\hline & $\mathrm{G}$, dyne $/ \mathrm{cm}^{2}$ & $12.5(10.4-15.2)^{* *}$ & & & \\
\hline & CLT, min & $32.7(29.7-34.2)^{*}$ & & & \\
\hline
\end{tabular}

For the reference drugs, the $\mathrm{IC}_{50}$ by the parameter MA was shown.

The level of statistical significance of differences of values compared with the control group: ${ }^{*} p \leq 0.001 ; * * p \leq 0.01 ; p=$ the level of statistical significance of differences of values between arterial and venous blood.

potential for aggregation, retraction, and release reaction, significantly increased by 2.7 -fold for venous and 4.2 -fold for arterial blood. The time to reach the maximum clot strength (TMA) dramatically decreased; its value for the venous blood reduced by $29.5 \%$ in comparison with the control. The parameter of clot strength $(\mathrm{G})$ in the venous blood was higher than the values in the control group by $45.8 \%$. Fibrinolysis parameters were characterized by the absence of statistical difference compared with healthy volunteers $(p=0.2)$.

\section{Group Deep Vein Thrombosis/ Pulmonary Arterial Thromboembolism (DVT/PATE)}

TEG results were characterized by an increase in the activity of thrombocytic component of hemostasis and the MA parameter increased on average by $46.9 \%$; the increase in time of clot formation and TMA parameter reduced on average by $39 \%$; elevation of clot strength and $\mathrm{G}$ parameter in arterial and venous sections of blood circulation increased by 2.3 -fold in comparison with the control. Fibrinolysis parameters, by compensation action, were likely to be characterized by increased activity. In the venous section of blood circulation, the CLT parameter reduced by $17.5 \%$ and $21.4 \%$ for the arterial and venous blood, respectively, in comparison to the control.

\section{Thrombosis modeling ex vivo by TEG method}

The results of registration of thromboelastograms of citrate blood samples, activated with TF and THR (Table 3), demonstrate the reduction in parameter $\mathrm{R}$, characterizing the time of the first fibrin thread formation (representing an enzymatic part of coagulation).

The time $\mathrm{R}$ reduced on average by $24.1 \%(p \leq 0.001)$ after adding TF and by $43.5 \%(p \leq 0.0001)$ after adding thrombin. The parameter Angle, characterizing the rate of fibrin network growth and its structure formation, significantly increased under the action of coagulation activators. This parameter elongated on average by $15.1 \%(p \leq 0.001)$ under the action of TF and by $23.5 \%$ under the action of thrombin $(p \leq 0.001)$. The parameter MA, characterizing the functional state of fibrinogen and activity of thrombocytes, under the action of thrombin and TF elongated on average by $42.7 \%$ in comparison with the control. The parameter clot strength $(\mathrm{G})$ was the most significant. This parameter under the conditions of coagulation activation by TF and thrombin significantly increased by 2.5 -fold. These results completely correlate with the literature data and are explained by the special role of excess thrombin and $\mathrm{TF}$ in thrombosis development (Podoplelova et al., 2016).

\section{Anti-aggregants study by TEG method}

The study drugs exerted different effects on the parameters of activated thromboelastograms. The anti-aggregant effect was characterized by a significant reduction in parameter MA; therefore, the comparison of experimental hypercoagulation with thromboelastogram data of the patients with thrombosis was conducted using the parameter $\mathrm{IC}_{50 \mathrm{MA}}$-concentration value, at which the parameter MA reduced by $50 \%$. In the presence of anti-aggregants, the parameters responsible for the coagulation hemostatic component $\mathrm{R}$ and Angle did not change. The antiaggregation activity of the chosen drugs was more effective after coagulation activation by the TF compared with thrombin.

Pentoxifylline concentration, after which parameter MA reduced by $50 \%$, was $4.4 \times 10^{-3} \mathrm{M} / 1$. $\mathrm{IC}_{50}$ of pentoxifylline in the control group was $1.4 \times 10^{-3} \mathrm{M} / 1$. The comparison of parameters of the concentration-effect function for the intact thrombocytes and thrombocytes in hyperactivity state demonstrated a threefold dose increase for a similar effect achievement. Similarly, more papaverine hydrochloride was required in compromised thrombocytes for the achievement of the effect of inhibiting 
Table 3. Dynamics of thromboelastograms parameters in the presence of the study substances, depending on the activator in concentration $10^{-3} \mathrm{M} / 1, \mathrm{Me}(25-75)$.

\begin{tabular}{|c|c|c|c|c|}
\hline \multicolumn{2}{|c|}{ Parameters } & \multirow{2}{*}{$\frac{\mathrm{CB}(\boldsymbol{n}=7)}{12.8(10.3-15.6)}$} & \multirow{2}{*}{$\frac{\mathbf{C B}+\mathbf{T F}(\boldsymbol{n}=\mathbf{7})}{9.7(7.4-10.6)^{\alpha}}$} & \multirow{2}{*}{$\begin{array}{c}\mathbf{C B}+\mathbf{T H R}(\boldsymbol{n}=\mathbf{7}) \\
7.2(5.1-8.7)^{\beta}\end{array}$} \\
\hline Control & $\mathrm{R}, \min$ & & & \\
\hline & Angle, deg & $44.7(39.8-49.4)$ & $51.4(49.1-53.8)^{\beta}$ & $56.3(53.6-59.8)^{\beta}$ \\
\hline & $\mathrm{MA}, \mathrm{mm}$ & $57.3(54.2-61.2)$ & $69.4(65.2-71.8)^{\beta}$ & $68.4(66.1-70.2)^{\beta}$ \\
\hline & $\mathrm{G}$, dyne $/ \mathrm{cm}^{2}$ & $5.7(4.5-8.1)$ & $17.5(13.6-20.7)^{\beta}$ & $18.6(16.4-19.2)^{\alpha \dagger}$ \\
\hline & CLT, min & $38.7(35.4-42.4)$ & $44.6(42.3-47.8)^{\alpha}$ & $45.6(43.2-47.4)^{\alpha}$ \\
\hline \multirow[t]{5}{*}{ Pentoxifylline } & $\mathrm{R}, \min$ & $14.6(13.2-15.8)$ & $9.5(8.4-10.4)$ & $8.4(7.2-9.4)$ \\
\hline & Angle, deg & $33.7(29.6-35.2)^{*}$ & $43.7(41.9-45.6)^{* *}$ & $47.8(44.8-48.2)^{* *}$ \\
\hline & $\mathrm{MA}, \mathrm{mm}$ & $41.8(39.8-45.6)^{*}$ & $53.7(51.2-55.6)^{* *}$ & $61.7(59.2-62.8) * *$ \\
\hline & $\mathrm{G}$, dyne $/ \mathrm{cm}^{2}$ & $4.1(3.6-4.4)^{* *}$ & $11.5(10.6-13.5)^{*}$ & $13.9(12.5-14.7)^{*}$ \\
\hline & CLT, min & $36.2(31.2-38.7)$ & $42.1(39.6-44.2)$ & $43.1(39.7-44.7)$ \\
\hline \multirow[t]{5}{*}{ Aspirin } & $\mathrm{R}, \min$ & $13.6(11.2-14.4)$ & $9.1(8.5-11.3)$ & $9.3(8.1-10.7)$ \\
\hline & Angle, deg & $33.7(29.6-35.2)^{* *}$ & $46.4(41.2-48.5)^{*}$ & $41.2(37.9-44.7)^{*}$ \\
\hline & $\mathrm{MA}, \mathrm{mm}$ & $36.3(31.2-39.5)^{*}$ & $44.7(41.2-48.5)^{* *}$ & $39.5(37.5-43.1)^{*}$ \\
\hline & $\mathrm{G}$, dyne $/ \mathrm{cm}^{2}$ & $3.7(3.1-4.6)^{*}$ & $8.4(7.2-9.4)^{* *}$ & $7.9(7.6-8.2)^{* *}$ \\
\hline & CLT, min & $38.4(36.7-39.4)$ & $39.6(37.4-40.2)$ & $36.2(34.1-39.8)$ \\
\hline \multirow[t]{5}{*}{ Papaverine hydrochloride } & $\mathrm{R}, \min$ & $12.3(10.6-14.2)$ & $9.3(8.5-10.3)^{\alpha}$ & $7.1(5.7-8.1)^{\beta}$ \\
\hline & Angle, deg & $36.4(34.2-39.5)$ & $51.3(48.6-54.3)^{\beta}$ & $54.3(51.6-56.4)^{\beta}$ \\
\hline & $\mathrm{MA}, \mathrm{mm}$ & $51.2(48.4-52.1)^{*}$ & $64.2(63.4-68.1)^{\beta}$ & $67.3(65.1-69.2)^{\beta}$ \\
\hline & $\mathrm{G}$, dyne $/ \mathrm{cm}^{2}$ & $4.4(4.1-6.2)$ & $15.6(12.1-17.4)^{\beta}$ & $15.4(13.7-16.2)^{\alpha \dagger}$ \\
\hline & CLT, $\min$ & $35.4(31.6-38.1)$ & $42.4(41.3-45.2)^{\alpha}$ & $44.3(41.2-46.3)^{\alpha}$ \\
\hline
\end{tabular}

${ }^{\alpha} p<0.05$.
${ }^{\beta} p<0.001-\mathrm{CB}+\mathrm{TF}$ or $\mathrm{CB}+\mathrm{THR}$ compared to $\mathrm{CB}$.
${ }^{*} p<0.05$.
${ }^{* *} p<0.001-$ compared to the control.
${ }^{\dagger} p<0.05-\mathrm{CB}+\mathrm{TF}$ compared to $\mathrm{CB}+\mathrm{TR}$.

thrombocyte aggregation by $50 \%\left(\mathrm{IC}_{50}\right.$ of the control group, 1.2 $\times 10^{-2} \mathrm{M} / \mathrm{l} ; \mathrm{IC}_{50}$ of the thrombocytes hyperactivity group, $5.6 \times$ $\left.10^{-2} \mathrm{M} / 1\right)$. In addition, acetylsalicylic acid in in vitro conditions is capable of correcting the hyperactivity of thrombocytes. The calculated $\mathrm{IC}_{50}$ of acetylsalicylic acid was $4.2 \times 10^{-3} \mathrm{M} / 1$ for the control group and $3.9 \times 10^{-3} \mathrm{M} / 1$ under the conditions of thrombocytes hyperactivity. Accordingly, the efficacy of aspirin under in vitro conditions in the initially compromised the increase in thrombocytes.

\section{DISCUSSION}

Preclinical and clinical studies of drug products regarding the hemostatic system allow researchers to reveal the changes, which may potentially lead to hypocoagulability or hypercoagulability.

Weingand et al. (1992) in a joint task force with the American Association for Clinical Chemistry's Division of Animal Clinical Chemistry and the American Society for Veterinary Clinical Pathology recommended prothrombin time (PT), activated partial thromboplastin time (APTT), and platelet counts as the minimal database for laboratory hemostatic testing in animal toxicity and safety studies. In addition, the joint task force described optimal blood collection procedures for use in hemostatic testing in animals. Later, the Joint Scientific Committee for International Harmonization of Clinical Pathology Testing made a similar recommendation of PT, APTT, or alternative and peripheral blood platelet count for the preclinical assessment of hemostasis (Weingand et al., 1996). Notably, tests assessing hypercoagulability or prothrombotic conditions are not mentioned in these recommendations.

To characterize the disorders in the coagulation cascade more accurately, a multiparameter panel has been proposed that assesses the internal, external, and general pathways of coagulation in preclinical GLP (Good Laboratory Practice) studies (Kurata and Horii, 2004) and clinical trials (Theus and Zbinden, 1984). Screening tests, APTT, PT, and thrombin time have been developed to identify deficiencies or inhibitors of coagulation factors that cause ineffective fibrin formation (Greener, 2005). However, these tests are not able to characterize the state of hypercoagulability. The routine laboratory thrombocyte assessment is limited to the parameters measured by the standard hematological analyzers, such as the number and parameters of peripheral blood thrombocytes, whereas the reactivity of thrombocytes is usually not assessed. The laboratory analyses of fibrinolysis and assessments of endothelial hemostatic properties were not recommended for the routine assessment in preclinical studies.

According to analysis data of the Health and Environmental Sciences Institute, Cardiac Biomarkers Working Group, directed on the assessment of safety of preclinical studies during the last 5 years, it was determined that the assessment of function of thrombocytes and fibrinolysis in preclinical and clinical studies for assessing the safety of drug products was not provided. Notably, this situation is determined by the lack of regulated methods of hemostatic system study that finally leads to financial 
losses. The problems of drugs were well assessed, especially for COX-2 inhibitions. For example, in 2004, 5 years after its approval by the FDA (U.S. Food and Drug Administration), Vioxx (rofecoxib), a potent COX-2 inhibitor, was voluntarily recalled from the market due to the increased risk of adverse cardiovascular thromboembolic events, including myocardial infarction and stroke (Ramot et al., 2007; van Adelsberg et al., 2007).

Up until now, numerous studies have been conducted on the epidemiology of thrombosis in various localizations, risk groups have been identified, and the spectrum and frequency of various episodes of thrombotic and thromboembolic complications have been established. To evaluate the representativeness of our sample in terms of the primary study objective, demographic characteristics and anamnesis data were chosen as the analysis criteria. For assessing the incidence of diabetes mellitus, oncological pathology, and smoking in patients with thrombosis, the initial data were analyzed by the method of paired tables using Pearson's $\chi^{2}$ test. The thrombosis rate in this age group did not depend on gender $(p=0.337)$, which corresponded to the literature data (Patrono et al., 2011). The smoking individuals were predominantly distributed in the thrombosis group $\left(\chi^{2}=3.947368 ; p=0.04694\right)$, which is consistent with the literature data on the contribution of smoking to an increase in thrombosis rate (Honda et al., 2014). Underlying diseases such as diabetes mellitus $\left(\chi^{2}=3.875271 ; p=0.03612\right)$ and oncological pathology $\left(\chi^{2}=4.159431 ; p=0.04235\right)$ with a different frequency remarkably promoted thrombosis development in this group that is proved by the results (Kodiatte et al., 2012). Because the primary objective of the study was to study the efficacy of anti-aggregants and a novel compound in thrombocytes in hyperaggregation state, an additional binary categorical variable was introduced to assess hyperaggregation frequency, which characterizes the parameters of thrombocytes aggregation other than reference values. In addition, by paired tables method using Pearson's $\chi^{2}$ test, it was found that the thromboses of the different localizations were accompanied by the hyperactivation of thrombocytes $\left(\chi^{2}=3.875271 ; p=\right.$ $0.0031)$. There was no significant difference in the frequency of the parameter sinus rhythm in thrombosis and control groups. However, the analysis of literature data demonstrates that this parameter does not correspond to the accurate predictor of thrombosis development (Konstantinides et al., 2014). Therefore, using the spectrum of marker points, the formed sample adequately correlated with the main population characteristics of patients with thrombosis and was acceptable for assessing the therapeutic efficacy of drugs under ex vivo conditions.

The results of this study show that the parameters of thromboelastograms of patients with deep vein thrombosis were comparable with those of healthy volunteers, activated by excess TF. The anti-aggregation activity of the chosen drugs was more effective when coagulation was activated by TF compared to thrombin. Different values of the effective concentrations for the same drug product demonstrate the necessity of the application of the assessment model of therapeutic efficacy in healthy volunteers as well as in initially compromised thrombocytes under ex vivo conditions.

Papaverine hydrochloride is of the greatest interest in this study. The main indication of papaverine is its use as an antispasmodic. The ability to inhibit the functional activity of thrombocytes was established long ago, after its widespread use as an antispasmodic (Serro-Azul et al., 1992). However, the use of papaverine as vasospasm arresting drug is often accompanied by undesirable clinical phenomena in the form of thrombocytopenia and bleeding, including those occurring due to the existing antiaggregation activity (Miller et al., 1995).

\section{CONCLUSION}

In this study, through the example of anti-aggregants with different mechanisms of action, the potential of TEG as a method for screening of products affecting hemostatic system, safety assessment method for hypercoagulability/ hypocoagulability, and thrombosis model using TF of thrombin as an activator were demonstrated. As it was illustrated through the example of papaverine hydrochloride, the timely assessment of the effect of potential drug products on the hemostatic system by the method of activated TEG allowed discovering the additional pharmacological effects of the drugs that were not planned to be used as anti-aggregants.

\section{AUTHORS' CONTRIBUTIONS}

All the authors contributed equally to this article.

\section{CONFLICT OF INTEREST}

The authors have no conflicts of interest to disclose.

\section{FUNDING}

None.

\section{REFERENCES}

Bakirov BA, Sakhautdinova IV, Maron AD. Peculiarities of the haemostatic system in pregnant patients with burdened obstetric anamnesis. Creat Surg Oncol, 2018; 8:125-9.

Greener M. Drug safety on trial. Last year's withdrawal of the anti-arthritis drug Vioxx triggered a debate about how to better monitor drug safety even after approval. EMBO Rep, 2005; 6:202-4.

Hackett T, Kelton JG, Powers P. Drug-induced platelet destruction. Semin Thromb Hemost, 1982; 8:116-37.

Honda T, Fujimoto K, Miyao Y, Koga H, Ishii M. Current cigarette smoking is an independent risk factor for subacute stent thrombosis in acute myocardial infarction patients. J Cardiol, 2014; 63:358-64.

Kodiatte TA, Manikyam UK, Rao SB, Jagadish TM, Reddy M, Lingaiah HK, Lakshmaiah V. Mean platelet volume in type 2 diabetes mellitus. J Lab Physicians, 2012; 4:5-9.

Konstantinides SV, Torbicki A, Agnelli G, Danchin N, Fitzmaurice D, Galiè N, Gibbs JSR, Huisman MV, Humbert M, Kucher N, Lang I, Lankeit M, Lekakis J, Maack C, Mayer E, Meneveau N, Perrier A, Pruszczyk P, Rasmussen LH, Schindler TH, Svitil P, Noordegraaf AV, Zamorano JL, Zompatori M, Zamorano JL, Achenbach S, Baumgartner H, Bax JJ, Bueno H, Dean V, Deaton C, Erol Ç, Fagard R, Ferrari R, Hasdai D, Hoes A, Kirchhof P, Knuuti J, Kolh P, Lancellotti P, Linhart A, Nihoyannopoulos P, Piepoli MF, Ponikowski P, Sirnes PA, Tamargo JL, Tendera M, Torbicki A, Wijns W, Windecker S, Erol Ç, Jimenez D, Ageno W, Agewall S, Asteggiano R, Bauersachs R, Becattini C, Bounameaux H, Büller HR, Davos CH, Deaton C, Geersing GJ, Sanchez MAG, Hendriks J, Hoes A, Kilickap M, Mareev V, Monreal M, Morais J, Nihoyannopoulos P, Popescu BA, Sanchez O, Spyropoulos AC. ESC Guidelines on the diagnosis and management of acute pulmonary embolism. Eur Heart $\mathrm{J}$ 2014; 35:3033-80.

Kurata M, Horii I. Blood coagulation tests in toxicological studies-review of methods and their significance for drug safety assessment. J Toxicol Sci, 2004; 29:13-32. 
Miller JA, Cross DT, Moran CJ, Dacey Jr. RG, McFarland JG, Diringer MN. Severe thrombocytopenia following intraarterial papaverine administration for the treatment of vasospasm. J Neurosurg, 1995; 83:435-7.

Patrono C, Andreotti F, Arnesen H, Badimon L, Baigent C, Collet JP, Caterina RD, Gulba D, Huber K, Husted S, Kristensen SD, Morais J, Neumann FJ, Rasmussen LH, Siegbahn A, Steg PG, Storey RF, Werf FV, Verheugt F. Antiplatelet agents for the treatment and prevention of atherothrombosis. Eur Heart J, 2011; 32:2922-32.

Podoplelova NA, Sveshnikova AN, Kotova YN, Eckly A, Receveur N, Nechipurenko DY, Obydennyi SI, Kireev II, Gachet C, Ataullakhanov FI, Mangin PH, Panteleev MA. Coagulation factors bound to procoagulant platelets concentrate in cap structures to promote clotting. Blood, 2016; 128:1745-55.

Ramot Y, Nyska A. Drug-induced thrombosis - experimental, clinical, and mechanistic considerations. Toxicol Pathol, 2007; 35:208-25.

Serro-Azul MI, Bydlowski SP, Chamone DA. Papaverine inhibits human platelet aggregation induced by ADP. Braz J Med Biol Res, $1992 ; 25: 521-8$.

Subramanian M, Kaplan LJ, Cannon JW. Thromboelastographyguided resuscitation of the trauma patient. JAMA Surg, 2019; 154(12):11523.

Theus R, Zbinden G. Toxicological assessment of the hemostatic system, regulatory requirements, and industry practice. Regul Toxicol Pharmacol, 1984; 4:74-95.

van Adelsberg J, Gann P, Ko AT, Damber JE, Logothetis C, Marberger M, Schmitz-Drager BJ, Tubaro A, Harms CJ, Roehrborn C. The VIOXX in prostate cancer prevention study: cardiovascular events observed in the rofecoxib $25 \mathrm{mg}$ and placebo treatment groups. Curr Med Res Opin, 2007; 23:2063-70.
Weingand K, Bloom J, Carakostas M, Hall R, Helfrich M, Latimer K, Levine B, Neptun D, Rebar A, Stitzel K, Troup C. Clinical pathology testing recommendations for nonclinical toxicity and safety studies. AACC-DACC/ASVCP joint task force. Toxicol Pathol, 1992; 20:539-43.

Weingand K, Brown G, Hall R, Davies D, Gossett K, Neptun D, Waner T, Matsuzawa T, Salemink P, Froelke W, Provost JP, Dal Negro G, Batchelor J, Nomura M, Groetsch H, Boink A, Kimball J, Woodman D, York M, Fabianson-Johnson E, Lupart M, Melloni E. Harmonization of animal clinical pathology testing in toxicity and safety studies. Fundam Appl Toxicol, 1996; 29:198-201.

\section{How to cite this article:}

Urakov AL, Mustafin IG, Nabiullina RM, Bashirova LI, Mochalov KS, Samorodov AV, Khaliullin FA, Lipatov DO, Korunas VI, Ismagilova LN, Khalimov AR. Thromboelastography as an instrument of preclinical studies of the potential drug. J Appl Pharm Sci, 2020; 10(08): 105-110. 